\title{
PROSPEK DAN STRATEGI PENGEMBANGAN EKOWISATA MANGROVE DI KELURAHAN TERITIP BALIKPAPAN
}

\author{
Ningsy Indrianti Junus ${ }^{1}$, H. Iwan Suyatna ${ }^{2}$ dan A. Syafei Sidik ${ }^{2}$ \\ ${ }^{1}$ Ilmu Magister Kehutanan, Fakultas Kehutanan, Universitas Mulawarman, Indonesia. \\ ${ }^{2}$ Fakultas Perikanan dan Ilmu Kelautan Universitas Mulawarman, Indonesia. \\ E-Mail: mugiwaraningsy@gmail.com
}

\begin{abstract}
ABSTRAK
Prospek Dan Strategi Pengembangan Ekowisata Mangrove Di Kelurahan Teritip Balikpapan. Tujuan dari penelitian ini adalah untuk menggambarkan prospek dan strategi pengembangan ekowisata mangrove di Teritip, Balikpapan Timur dan potensi pengembangan ekowisata di hutan bakau. Kawasan mangrove di Kecamatan Teritip, Balikpapan Timur adalah eksploitasi oleh masyarakat setempat seperti konversi hutan mangrove menjadi area tambak, pemukiman, pemotongan kayu untuk kayu bakar. Tujuan utama dari penelitian ini adalah untuk merumuskan strategi ekowisata mangrove berkelanjutan di Teritip. Hasil penelitian menunjukkan bahwa Ekoturisme Mangrove Teritip memiliki aspek potensial untuk dikembangkan dalam rujukan ke tempat ekologi, sumber daya alam termasuk flora dan fauna.
\end{abstract}

Kata kunci : Ekowisata bakau, teritip, strategi pembangunan.

\section{ABSTRACT}

Mangrove Ecowisata Development Prospect And Strategy In Vocational Schools Balikpapan. The aim of the research are to describe prospect and development strategy of mangrove ecoturism in Teritip, East Balikpapan and the potential of ecotourism development in mangrove forest. Mangrove area at Sub distric Teritip, East Balikpapan was exploitation by local community such as conversion of mangrove forest to fishpond area, settlement,cutting of wood for firewood. The main objective of this research was to formulated strategy of sustainable mangrove ecoturism at Teritip. The result showed that the Mangrove Ecoturism Teritip has potential aspects to develop in reffering to the ecology place, the natural resources including flora and fauna.

Key words : Mangrove ecoturism, teritip, development strategy.

\section{PENDAHULUAN}

Ekowisata merupakan suatu kegiatan wisata berbasis lingkungan yang mengutamakan upaya-upaya pelestarian lingkungan (alam dan budaya) dan meningkatkan partisipasi masyarakat dalam pengelolaannya, sehingga dapat meningkatkan perekonomian masyarakat sekitar daerah tujuan wisata.

Ekowisata sangat tepat dan berdaya guna dalam mempertahakankan keutuhan dan keaslian ekosistem. Dilihat dari sudut ekologi, wilayah pesisir dan laut merupakan tempat hidup beberapa ekosistem yang unik dan saling terkait, dinamis, dan produktif. Oleh karena itu ekowisata dirasa tepat sebagai solusi dalam melestarikan ekosistem pesisir yang salah satunya adalah ekosistem mangrove

Teritip merupakan wilayah pesisir yang berada di sebelah Timur Balikpapan. Hutan mangrove yang berada di Teritip memiliki potensi yang cukup besar dan bisa dimanfaatkan sebagai objek ekowisata dengan mengutamakan aspek konservasi alam, pemberdayaan, sosial ekonomi, budaya masyarakat lokal dan pembelajaran serta pendidikan. Karakteristik dari hutan 
mangrove yang berada di Teritip adalah hutan mangrove yang langsung berhadapan dengan laut, oleh sebab itu pentingnya menjaga dan melestarikan hutan mangrove yang memiliki fungsi untuk masyarakat yang tinggal di wilayah pesisir.

Tujuan dari penelitian ini adalah untuk mengetahui Apa saja potensi dan bagaimana kondisi hutan mangrove di Teritip, bagaimana kesesuaian dan daya dukung kawasan magrove di Teritip dan faktor-faktor apa saja yang mendukung strategi pengembangan ekowisata mangrove di Kelurahan Teritip Balikpapan.

\section{METODA PENELITIAN}

\subsection{Tempat dan Waktu}

Penelitian dilaksanakan di di Kelurahan Teritip, Balikpapan. Pada bulan MeiJuni 2019.

\subsection{Bahan dan Alat}

Alat dan bahan yang akan dipergunakan dalam penelitian ini adalah sebagai berikut : Form kuisioner dan alat pendukung wawancara.

\subsection{Metode Penelitian}

Metode penelitian secara garis besar terdiri atas survei lokasi, penentuan stasiun pengamatan dan pengumpulan data yang diperlukan. Pengumpulan data terdiri dari dua yaitu data primer (pengamatan kerapatan dan jenis mangrove, ketebalan mangrove, pengukuran ketebalan mangrove, observasi objek biota dan wawancara) sedangkan data sekunder (mengamati pasang surut dan studi pustaka).

\subsection{Analisis Data}

\subsubsection{Analisis Data Vegetasi} Mangrove

a. Kerapatan Spesies
Menurut Bengen (2004), Kerapatan jenis (Di) adalah jumlah individu jenis $i$ dalam suatu unit area :

$$
D i=\frac{n i}{A}
$$

Keterangan :

$n i=$ Jumlah total tegakan ke $-i$ (individu $/ \mathrm{m}^{2}$ )

$\mathrm{A}=$ Luas total area pengambilan contoh $\left(\mathrm{m}^{2}\right)$

b. Kerapatan Total

Kerapatan total adalah jumlah semua individu mangrove dalam suatu unit area yang dinyatakan sebagai berikut

Kerapatan Total $=\sum n / A$

Keterangan :

$\sum n=$ Jumlah total individu seluruh spesies

$n i=$ Jumlah total individu dari spesies ke-i

$\mathrm{A}=$ Luas area total pengambilan contoh (luas total petak contoh)

\subsubsection{Analisis Kesesuaian Wisata Mangrove}

Rumus yang digunakan untuk kesesuaian wisata pantai dan wisata bahari adalah (Yulianda, 2007):

$$
\mathrm{IKW}=\sum\left(\frac{\text { Mi }}{\operatorname{Mmax}}\right) \times 100 \%
$$

Keterangan:

IKW = Indeks Kesesuaian Wisata.

$\mathrm{Ni}=$ Nilai parameter ke-I (bobot $\mathrm{x}$ skor)

Nmaks = Nilai maksimum dari suatu kategori wisata.

Penentuan kesesuaian berdasarkan perkalian skor dan bobot yang diperoleh dari setiap parameter. Kesesuaian kawasan dilihat dari tingkat persentase kesesuaian yang diperoleh penjumlah nilai dari seluruh parameter. 
Tabel 1. Matriks kesesuaian lahan untuk wisata pantai kategori wisata mangrove

\begin{tabular}{|c|c|c|c|c|c|c|c|c|c|c|}
\hline \multirow{2}{*}{ No } & \multirow{2}{*}{ Parameter } & \multirow{2}{*}{ Bobot } & \multicolumn{4}{|c|}{ Kategori } & \multicolumn{4}{|c|}{ Skor } \\
\hline & & & S1 & S2 & S3 & $\mathbf{N}$ & S1 & S2 & S3 & $\mathbf{N}$ \\
\hline 1 & $\begin{array}{l}\text { Ketebalan } \\
\text { Mangrove (m) }\end{array}$ & 5 & $>500$ & $\begin{array}{c}>200- \\
500\end{array}$ & $50-200$ & $<50$ & 4 & 3 & 2 & 1 \\
\hline 2 & $\begin{array}{l}\text { Kerapatan } \\
\text { Mangrove (100 } \\
\mathrm{m} 2)\end{array}$ & 4 & $>15-25$ & $>10-15$ & $10-5$ & $<5$ & 4 & 3 & 2 & 1 \\
\hline 3 & Jenis Mangrove & 4 & $>5$ & $3-5$ & $1-2$ & 0 & 4 & 3 & 2 & 1 \\
\hline 4 & Pasang Surut & 3 & $0-1$ & $>1-2$ & $>2-5$ & $>5$ & 4 & 3 & 2 & 1 \\
\hline 5 & Objek Biota & 3 & $\begin{array}{c}\text { Ikan, } \\
\text { Udang, } \\
\text { Kepiting, } \\
\text { Moluska, } \\
\text { Reptile, } \\
\text { Burung } \\
\text { dan } \\
\text { monyet }\end{array}$ & $\begin{array}{c}\text { Ikan, } \\
\text { Udang, } \\
\text { Kepiting, } \\
\text { Moluska, }\end{array}$ & $\begin{array}{c}\text { Ikan, } \\
\text { Moluska, }\end{array}$ & $\begin{array}{c}\text { salah satu } \\
\text { biota air }\end{array}$ & 4 & 3 & 2 & 1 \\
\hline
\end{tabular}

Sumber : Yulianda (2007)

Keterangan $\quad:$ Nilai maksimum $=76$

$\mathrm{S} 1$ = Sangat sesuai, dengan nilai $80 \%-100 \%$

$\mathrm{S} 3=$ Sesuai bersyarat, dengan nilai $35 \%-<60 \%$

\subsubsection{Analisis Daya Dukung}

Metode yang diperkenalkan untuk menghitung daya dukung pengembangan ekowisata alam adalah dengan menggunakan konsep Daya Dukung Kawasan (DDK). DDK adalah jumlah maksimum pengunjung yang secara fisik dapat ditampung di kawasan yang disediakan pada waktu tertentu tanpa menimbulkan gangguan pada alam dan manusia. Perhitungan DDK dalam bentuk rumus adalah sebagai berikut (Yulianda, 2007):

$$
D D K=k \times \frac{L p}{L t} \times \frac{W t}{W p}
$$

Keterangan:

DDK = Daya Dukung Kawasan (orang/hari).

$\mathrm{k}=$ = Potensi ekologis pengunjung per satuan unit area (orang).

Lp = Panjang area yang dapat dimanfaatkan (m).

Lt $=$ Unit area untuk kategori tertentu (m).

$\mathrm{W} \quad=$ Waktu yang disediakan oleh kawasan untuk kegiatan wisata
$\mathrm{S} 2=$ Sesuai, dengan nilai $60 \%-$ $<80 \%$

$\mathrm{N}=$ Tidak sesuai, dengan nilai $<35 \%$

dalam satu hari (jam/hari).

$\mathrm{Wp}=$ Waktu yang dihabiskan oleh pengunjung (jam/hari).

\subsubsection{Analisis SWOT}

Analisis SWOT digunakan untuk mengkaji langkah strategis pengembangan ekowisata hutan mangrove di Kelurahan Teritip Kota Balikpapan. Identifikasi faktor internal dan eksternal kawasan diperlukan sebagai langkah dari formulasi pengembangan strategis kawasan. Faktor internal kawasan meliputi kekuatan (Strength) dan kelemahan (Weakness) yang terdapat di Gosong Batu Lampe, sedangkan faktor eksternal meliputi kesempatan (Oppprtunity) dan ancaman (Threat).

Analisis data secara kualitatif dilakukan terhadap penentuan faktor-faktor internal dan eksternal yang dikaji berdasarkan data wawancara dan pengamatan di lokasi penelitian. Analisis secara kuantitatif dilakukan terhadap pembobotan, penetapan rating, pemberian skor pada 
hingga penentuan rangking pada strategi pengembangan ekowisata (Jayanti 2009).

\section{HASIL PENELITIAN DAN PEMBAHASAN}

\subsection{Kondisi Sumberdaya Pesisir} (Ekosistem Mangrove)
Berdasarkan hasil penelitian vegetasi mangrove yang berada di Teritip terdapat 5 (lima) jenis, yaitu Avicennia alba, Nypa Fruticans, Rhizophora apiculata, Rhizophora mucronata dan Sonneratia alba. Komposisi dan kerapatan mangrove pada Teritip dapat dilihat pada Tabel 2 berikut:

Tabel 2. Komposisi vegetasi mangrove di Teritip

\begin{tabular}{clccc}
\hline \multirow{2}{*}{ No } & \multicolumn{1}{c}{ Spesies } & \multicolumn{3}{c}{ Kerapatan per/stasiun (Individu/ha) } \\
\cline { 3 - 5 } & Avicennia alba & 35 & 399 & $\mathbf{4}$ \\
\hline 1 & Nypa Fruticans & - & 42 & - \\
2 & Rhizophora apiculata & - & - & 362 \\
3 & Rhizophora mucronata & 51 & 72 & 197 \\
4 & Sonneratia alba & 69 & 544 & 603 \\
5 & Jumlah & $\mathbf{1 5 5}$ & $\mathbf{1 0 5 7}$ & $\mathbf{1 5 8 4}$ \\
\hline
\end{tabular}

Sumber : Data primer yang diolah, 2019

Kerapatan jenis mangrove di Teritip berkisar antara $35 \mathrm{ind} / \mathrm{ha}-603$ ind/ha. Jenis mangrove yang memiliki kerapatan tertinggi yaitu Sonneratia alba pada stasiun 4 sebesar 603 ind/ha. Sementara jenis mangrove yang memiliki kerapatan rendah adalah Avicennia alba pada stasiun 1 sebesar 35 ind/ha. Mangrove jenis Sonneratia alba mendominasi tutupan lahan ekosistem mangrove di Teritip dimana wilayah mangrove teritip yang langsung berhadapan dengan laut, zona yang paling dekat dengan laut biasanya didominasi oleh jenis-jenis Avicennia dan Sonneratia. Hal ini dikarenakan oleh karakteristik penyebarannya sangat mudah dan dapat tumbuh secara alami dengan baik.

\subsection{Kelayakan dan Daya Dukung}

Lingkungan Sumberdaya Pesisir

Kawasan ekowisata merupakan bagian dari wisata alam sehingga perlu diketahui kesesuaian dan daya dukung kawasan suatu wilayah untuk wisata. Sumberdaya Teritip untuk nilai indeks kesesuaian ekowisata mangrove :

\subsection{Kesesuaian Ekowisata Mangrove}

Berdasarkan hasil penelitian untuk pengukuran parameter kesesuaian ekowisata mangrove di Teritip, Balikpapan tingkat kesesuaian ekowisata pada stasiun 1, 2 dan 3 ditampilkan, berikut :

Tabel 3. Indeks Kesesuaian Ekowisata Mangrove pada Stasiun 1

\begin{tabular}{clcccc}
\hline No. & \multicolumn{1}{c}{ Parameter } & $\begin{array}{c}\text { Hasil } \\
\text { Observasi }\end{array}$ & Bobot & Skor & Bobot*Skor \\
\hline 1 & Ketebalan Mangrove $(\mathrm{m})$ & 31 & 5 & 1 & 5 \\
2 & Kerapatan Mangrove $\left(100 \mathrm{~m}^{2}\right)$ & 155 & 4 & 4 & 16 \\
3 & Jenis Mangrove & 3 & 4 & 3 & 12 \\
4 & Pasang Surut (m) & 1,4 & 3 & 3 & 9 \\
5 & Biota & 4 & 3 & 3 & 9 \\
\hline
\end{tabular}




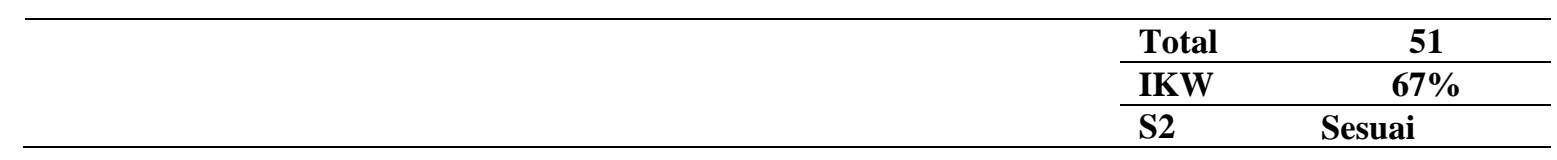

Sumber : Data sekunder 2019 ; data primer yang diolah, 2019

Tabel 4 . Indeks kesesuaian ekowisata mangrove pada Stasiun 2.

\begin{tabular}{clcccc}
\hline No. & \multicolumn{1}{c}{ Parameter } & $\begin{array}{c}\text { Hasil } \\
\text { Observasi }\end{array}$ & Bobot & Skor & Bobot*Skor \\
\hline 1 & Ketebalan Mangrove $(\mathrm{m})$ & 73 & 5 & 2 & 10 \\
2 & Kerapatan Mangrove $\left(100 \mathrm{~m}^{2}\right)$ & 1057 & 4 & 4 & 16 \\
3 & Jenis Mangrove & 4 & 4 & 3 & 12 \\
4 & Pasang Surut $(\mathrm{m})$ & 1,4 & 3 & 3 & 9 \\
5 & Biota & 5 & 3 & 4 & 12 \\
\hline & & & & Total & $\mathbf{5 9}$ \\
\cline { 3 - 5 } & & & SKW & S8\% \\
\hline
\end{tabular}

Sumber : Data sekunder 2019 ; Data primer yang diolah, 2019

Tabel 5 . Indeks kesesuaian ekowisata mangrove pada Stasiun 3.

\begin{tabular}{clcccc}
\hline No. & \multicolumn{1}{c}{ Parameter } & $\begin{array}{c}\text { Hasil } \\
\text { Observasi }\end{array}$ & Bobot & Skor & Bobot*Skor \\
\hline 1 & Ketebalan Mangrove $(\mathrm{m})$ & 88 & 5 & 2 & 10 \\
2 & Kerapatan Mangrove $\left(100 \mathrm{~m}^{2}\right)$ & 1584 & 4 & 4 & 16 \\
3 & Jenis Mangrove & 4 & 4 & 3 & 12 \\
4 & Pasang Surut $(\mathrm{m})$ & 1,4 & 3 & 3 & 9 \\
5 & Biota & 3 & 3 & 4 & 12 \\
\hline & & & & Total & $\mathbf{5 9}$ \\
\cline { 3 - 5 } & & & SKW & Sesuai \\
\hline
\end{tabular}

Sumber : Data sekunder 2019 ; Data primer yang diolah, 2019

Berdasarkan hasil perhitungan menggunakan rumus Indeks Kesesuaian Wisata (IKW) didapatkan kategori tingkat kesesuaian lahan masing-masing

Tabel 6. Indeks kesesuaian ekowisata mangrove di Teritip

\begin{tabular}{cccc}
\hline Lokasi Pengamatan & Total Skor & IKW $(\boldsymbol{\%})$ & Tingkat Kesesuaian \\
\hline Stasiun 1 & 51 & 67 & S2 \\
Stasiun 2 & 59 & 78 & S2 \\
Stasiun 3 & 59 & 78 & S2 \\
\hline
\end{tabular}

Sumber : Data primer yang diolah, 2019

Indeks kesesuaian ekowisata mangrove memiliki nilai penting terhadap pengelolaan suatu kawasan pesisir berdasarkan faktor-faktor yang mempengaruhi kegiatan ekowisata mangrove. Nilai indeks kesesuaian stasiun pengamatan di Kelurahan Teritip Kota Balikpapan, dapat dilihat pada Tabel 6. 
1 sebesar $67 \%$, stasiun 2 sebesar $78 \%$ dan stasiun 3 sebesar $78 \%$. Sehingga pada stasiun 1, 2 dan 3 memiliki nilai pada kisaran nilai indeks kesesuaian wisata $60 \%$ - $<80 \%$ maka masuk pada kategori sesuai (S2) untuk kegiatan ekowisata mangrove. Dengan demikian maka pada seluruh stasiun mangrove di Teritip dapat direkomdasikan sebagai destinasi utama ekowisata mangrove dengan syarat kesesuaian wisata yang memenuhi persyaratan dalam kajian wisata.

\subsection{Daya Dukung Kawasan Gosong Batu Lampe}

Luas daerah pemanfaatan yang dapat dimanfaatkan sebagai area wisata mangrove di Kelurahan Teritip Kota Balikpapan sekitar $300.000 \mathrm{~m}^{2}$. Daya dukung dihitung untuk mendapatkan jumlah pengunjung maksimum yang dapat diterima oleh kawasan pada stasiun pengamatan. Daya dukung untuk kategori sesuai (S2) didapatkan jumlah wisatawan yang dapat ditampung setiap hari adalah sebesar 800 orang/hari, hal ini dapat diartikan bahwa jalur ekowisata secara fisik mampu menampung sejumlah pengunjung tersebut setiap hari. Daya dukung kawasan dihitung dengan mempertimbangkan luas area yang dimanfaatkan untuk kegiatan wisata serta estimasi waktu yang dihabiskan oleh pengunjung.
3.5. Strategi Pengembangan Ekowisata Mangrove Di Kelurahan Teritip Balikpapan

Penyusunan faktor-faktor internal dan eksternal tersebut diperoleh dengan wawancara secara mendalam (in-depth interview) dengan narasumber yang mengerti tentang ekowisata mangrove sebanyak 6 jiwa yang mencakup representasi dari pemegang kebijakan dalam pengelolaan dan pemanfaatan ekowisata mangrove di Kelurahan Teritip yaitu :

a. Dinas Pertanian, Kelautan dan Perikanan Kota Balikpapan

b. Kelompok Masyarakat Pengawas (Pokmaswas)

c. Kepolisian Air dan Udara (POLAIRUD)

d. Pengunjung

Analisis data dan informasi yang diperoleh dari wawancara di atas yaitu dibuatkan suatu matriks. Adapun hasil identifikasi faktor kekuatan, kelemahan, peluang dan ancaman untuk penyusunan strategi kebijakan untuk meningkatkan prospek dan pengembangan sumberdaya ekowisata mangrove di Kelurahan Teritip dapat disajikan sebagai berikut :

Hasil evaluasi faktor internal ini didapat berdasarkan data dari narasumber yang diambil Kelurahan Teritip sebanyak 6 jiwa 40 Jiwa. Matriks tersebut dapat dilihat pada Tabel 7 berikut.

Tabel 7. Matriks Evaluasi Faktor Internal (IFE Matrix) Prospek dan Strategi Pemanfaatan dan Pengelolaan Wisata Mangrove di Kelurahan Teritip

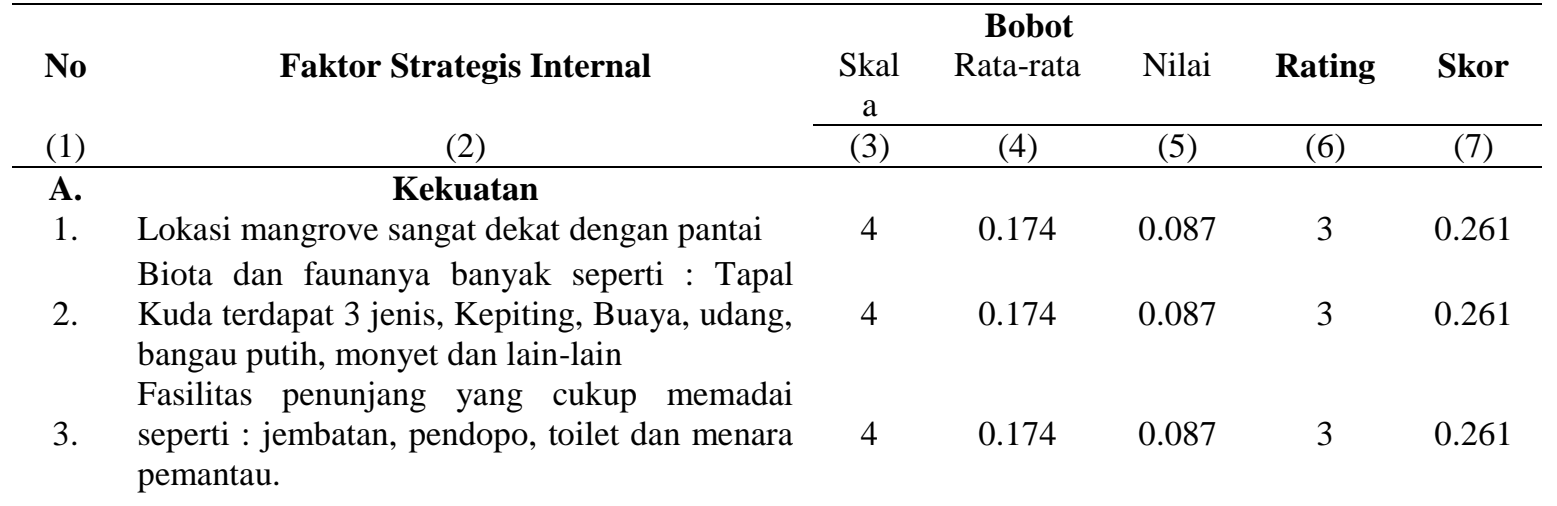




\begin{tabular}{|c|c|c|c|c|c|c|}
\hline 4. & $\begin{array}{l}\text { Tiket masuk yang cukup terjangkau : Motor } \\
\text { Rp. } 5000 \text {, Mobil Rp. } 10000 \text {. }\end{array}$ & 3 & 0.130 & 0.065 & 3 & 0.196 \\
\hline 5. & Hutan mangrove yang masih asri & 4 & 0.174 & 0.087 & 4 & 0.348 \\
\hline \multirow[t]{2}{*}{6.} & Kerapatan mangrove tinggi & 4 & 0.174 & 0.087 & 4 & 0.348 \\
\hline & Sub Jumlah & 23 & 1 & 0.500 & & 1.674 \\
\hline \multirow{2}{*}{$\begin{array}{l}\text { No } \\
\text { B. }\end{array}$} & Faktor Strategis Internal & & Bobot & & Rating & Skor \\
\hline & & $\begin{array}{c}\text { Skal } \\
\mathrm{a} \\
\end{array}$ & Rata-rata & Nilai & & \\
\hline (1) & $(2)$ & (3) & $(4)$ & (5) & $(6)$ & (7) \\
\hline No & Faktor Strategis Internal & & Bobot & & Rating & Skor \\
\hline 1. & Ketebalan mangrovenya rendah & 1 & 0.125 & 0.063 & 2 & 0.125 \\
\hline 2. & Tidak adanya air bersih di lokasi wisata. & 1 & 0.125 & 0.063 & 2 & 0.125 \\
\hline 3. & $\begin{array}{l}\text { Tidak adanya warung/ rumah makan dan } \\
\text { penginapan. }\end{array}$ & 1 & 0.125 & 0.063 & 1 & 0.063 \\
\hline 4. & Akses trasportasi yang belum memadai & 1 & 0.125 & 0.063 & 1 & 0.063 \\
\hline 5. & Kurangnya pengunjung yang datang & 2 & 0.250 & 0.125 & 2 & 0.250 \\
\hline \multirow[t]{3}{*}{6.} & $\begin{array}{l}\text { Tidak adanya penjaga keaman di lokasi wisata } \\
\text { mangrove }\end{array}$ & 2 & 0.250 & 0.125 & 2 & 0.250 \\
\hline & Sub Jumlah & 8 & 1 & 0.500 & & 0.875 \\
\hline & Jumlah & & & 1.000 & & 2.549 \\
\hline
\end{tabular}

Sumber : Data Primer, 2019

Berdasarkan dari Tabel 7 di atas menunjukan nilai skor kekuatan dan kelemahan 2,549. Hal ini menunjukan bahwa wilayah wisata mangrove di Kelurahan Teritip memiliki faktor strategis internal (kekuatan) yang dapat dimaksimalkan dengan memanfaatkan nilai ekonomi untuk meningkatkan pengelolaan dan pemanfaatan wilayah wisata mangrove yang berkelanjutan, dengan memanfaatkan dan mengelola kelebihan yang ada seperti : lokasi mangrove yang sangat dekat dengan pantai, memiliki biota dan fauna yang cukup banyak, fasilitas penunjang yang cukup memadai, hutan mangrove yang masih asri dan kerapatan mangrove yang masih tinggi.
Kelemahan utama dalam prospek meningkatkan pemanfaatan dan pengelolaan wilayah wisata mangrove di Kelurahan Teritip yaitu ketebalan mangrove rendah, tidak adanya air bersih, tidak adanya warung/rumah makan dan penginapan, kurangnya pengunjung yang datang dan tidak adanya penjaga keamanan di lokasi wisata mangrove. Hal ini yang menjadi permasalahan yang belum mampu diatasi oleh stakeholder dengan alasan terbentur dengan tidak memiliki dana. dimana jika ingin menjadikan tempat wisata mangrove jauh lebih baik maka diperlukanlah tidak sedikit dana.

Tabel 8. Matriks Evaluasi Faktor Eksternal (IFE Matrix) Prospek dan Strategi dalam Pemanfaatan dan Pengelolaan Wisata Mangrove di Kelurahan Teritip

\begin{tabular}{ccccccc}
\hline No & \multicolumn{2}{c}{ Faktor Strategis Eksternal } & $\begin{array}{c}\text { Bobot } \\
\text { Skal } \\
\text { Rata-rata }\end{array}$ & Nilai & Rating & Skor \\
\hline$(1)$ & \multicolumn{1}{c}{$(2)$} & $(3)$ & $(4)$ & $(5)$ & $(6)$ & $(7)$ \\
\hline $\begin{array}{c}\text { A. } \\
\text { 1. }\end{array}$ & $\begin{array}{l}\text { Leluangan cukup luas } \\
\text { 2. }\end{array}$ & 4 & 0.174 & 0.125 & 4 & 0.500 \\
& $\begin{array}{l}\text { Peluang ekonomi } \\
\text { wisata mangrove. }\end{array}$
\end{tabular}


3. Adanya dukungan dari pihak stakeholder. Adanya kemitraan dalam kerja sama antara pokmaswas dan Dinas Pertanian, Kelautan dan Perikanan dalam pengelolaan dan pemanfaatan wilayah wisata mangrove

5. Dapat dijadikan tempat edukasi dan penelitian

5. mahasiswa

6. Dapat menambah wahana wisata Sub Jumlah

B. Ancaman

1. Dekatnya lokasi wisata dengan tambak
masyarakat

Adanya satwa liar seperti : ular phytton, buaya

2. dan biawak

3. Banyaknya sampah plastik

4. Seringnya batang mangrove yang di

4. eksploitasi masyarakat

5. Area parkir yang masih dimiliki warga sekitar

6. Lokasi wisata mangrove yang akan dijadikan pelabuhan kapal

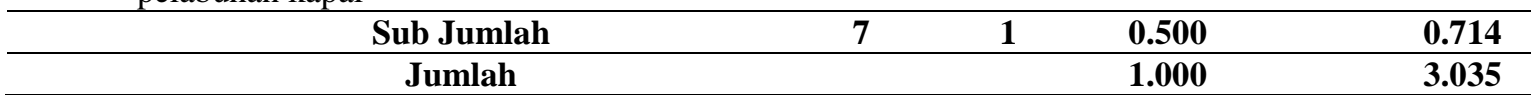

Sumber : Data primer, 2019

Berdasarkan Tabel 8, hasil Evaluasi Faktor Eksternal (EFE Matrik) memberikan nilai skor sebesar 2,321. Hal ini menunjukan bahwa wilayah wisata mangrove memiliki faktor strategis eksternal (peluang) dimana memiliki lahan yang cukup luas, peluang ekonomi yang tinggi, adanya dukungan dari pihak stakeholder, adanya kemitraan dalam kerjasama antara Pokmaswas dengan Dinas Pertanian, Kelautan dan Perikanan, dapat dijadikan edukasi dan penelitian mahasiswa serta dapat menambah wahana wisata. Sehingga daerah wisata mangrove di Kelurahan Teritip memiliki potensi yang sangat luas untuk pengembangan pariwisata dan meningkatkan ekonomi masyarakat sekitar. Perlunya promosi yang lebih aktif lagi agar daerah wisata mangrove dapat dikenal lebih luas lagi oleh masyarakat lokal maupun luar Kelurahan Teritip.

Sedangkan ancaman yang terdapat di daerah wisata mangrove Kelurahan Teritip tidak terlalu besar dapat dilihat dari hasil analisis SWOT ancaman yang ada di daerah wisata mangrove yakni : 0,714 . Untuk mengurangi ancaman yang ada di daerah wisata mangrove Kelurahan Teritip perlunya perhatian khusus baik itu dari pemerintah setempat, warga maupun pihak-pihak yang terkait agar segala ancaman dapat diminimalisir secara baik.

Sub jumlah faktor strategi internal (kekuatan dan kelemahan) dan sub jumlah faktor strategi eksternal (peluang dan ancaman dapat dituangkan dalam satu diagram atau grafik cretasius sebagaimana yang ditampilkan pada diagram. Lebih jelasnya dapat dilihat pada Diagram di bawah ini. 


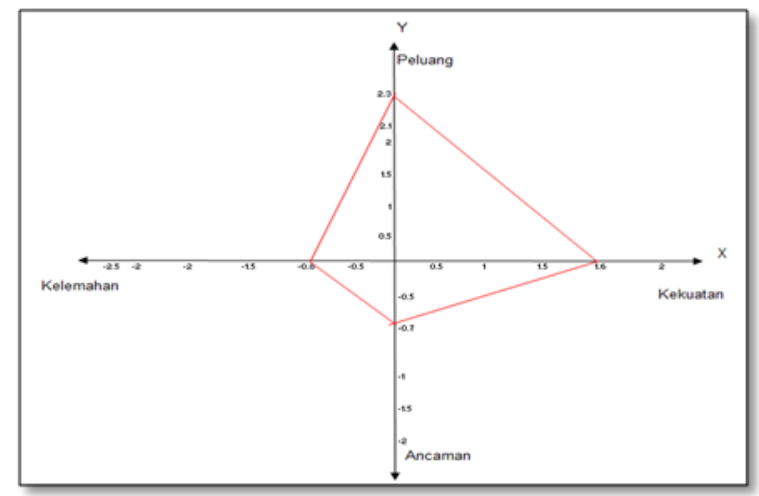

Diagram 1. Posisi titik Analisis SWOT

Faktor strategi yang berasal dari kekuatan memilki pengaruh yang lebih besar yaitu 2,321 dari pada pengaruh faktor strategi ancaman yang nilainya hanya sebesar 0,714 demikian pula faktor strategi kekuatan yang nilainya 1,674 memiliki pengaruh yang lebih kuat dari faktor strategi kelemahan yang hanya memiliki nilai 0,875. Berdasarkan diagram di atas dapat disimpulkan prospek dan strategi dalam mengembangkan dan mengelola wilayah wisata mangrove di Kelurahan Teritip berdasarkan wilayah lokasi wisata

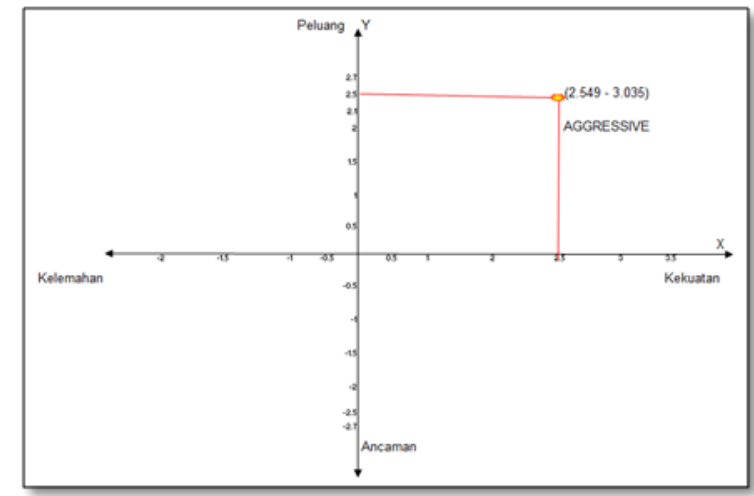

Diagram 2. Hasil Interpretasi Analisis SWOT

mangrove berada kuadrant I yang artinya bersifat Aggressive, hal ini dapat dilihat bahwa peluang untuk prospek pengembangan wisata mangrove sangat besar sehingga untuk menjadi tempat ini merupakan wisata mangrove yang bagus dan diminati wisatawan terbuka lebar, untuk pengembangan kesejahteraan masyarakat sekitar dengan meningkatkan ekonomi juga sangat menjanjikan.

Keseluruhan strategi-strategi penanganan peningkatan pengelolaan dan pemanfaatan wilayah pesisir dapat dilihat pada Tabel 9.

Tabel 9. Matriks Evaluasi Faktor Eksternal (IFE Matrix) Prospek dan Strategi dalam Pemanfaatan dan Pengelolaan Wisata Mangrove di Kelurahan Teritip

\begin{tabular}{|c|c|c|}
\hline & KEKUATAN (S) & KELEMAHAN (W) \\
\hline $\begin{array}{l}\text { Analisis } \\
\text { Internal }\end{array}$ & $\begin{array}{l}\text { 1. Lokasi mangrove sangat dekat } \\
\text { dengan pantai. } \\
\text { 2. Biota dan faunanya banyak } \\
\text { seperti : Tapal Kuda terdapat } 3 \\
\text { jenis, Kepiting, Buaya, udang, } \\
\text { bangau putih, monyet dan lain- } \\
\text { lain. } \\
\text { 3. Fasilitas penunjang yang } \\
\text { cukup memadai seperti : } \\
\text { jembatan, pendopo, toilet dan } \\
\text { menara pemantau. } \\
\text { 4. Tiket masuk yang cukup } \\
\text { terjangkau : Motor Rp. 5000, } \\
\text { Mobil Rp.10000. } \\
\text { 5. Hutan mangrove yang masih } \\
\text { asri. } \\
\text { 6. Kerapatan mangrove tinggi. }\end{array}$ & $\begin{array}{l}\text { 1. Ketebalan mangrovenya rendah. } \\
\text { 2. Tidak adanya air bersih di lokasi } \\
\text { wisata. } \\
\text { 3. Tidak adanya warung/ rumah } \\
\text { makan dan penginapan. } \\
\text { 4. Akses trasportasi yang belum } \\
\text { memadai. } \\
\text { 5. Kurangnya pengunjung yang } \\
\text { datang. } \\
\text { 6. Tidak adanya penjaga keaman di } \\
\text { lokasi wisata mangrove }\end{array}$ \\
\hline $\begin{array}{l}\text { Analisis } \\
\text { LingkunganEksternal }\end{array}$ & & \\
\hline
\end{tabular}




\begin{tabular}{|c|c|c|}
\hline PELUANG (O) & $\begin{array}{c}\text { Strategi Menggunakan } \\
\text { Kekuatan Untuk } \\
\text { Memanfaatkan Peluang (S-O) }\end{array}$ & $\begin{array}{c}\text { Strategi Mengurangi Kelemahan } \\
\text { Dengan Memanfaatkan Peluang } \\
(\mathrm{W}-0)\end{array}$ \\
\hline $\begin{array}{l}\text { 1. Lahan cukup luas. } \\
\text { 2.Peluang ekonomi yang } \\
\text { tinggi di kawasan wisata } \\
\text { mangrove. } \\
\text { 3. Adanya dukungan dari } \\
\text { pihak stakeholder. } \\
\text { 4. Adanya kemitraan dalam } \\
\text { kerja sama antara } \\
\text { pokmaswas dan Dinas } \\
\text { Pertanian, Kelautan dan } \\
\text { Perikanan } \\
\text { pengelolaan dalam } \\
\text { pemanfaatan } \\
\text { wisata mangrove. } \\
\text { 5.Dapat dijadikan tempat } \\
\text { edukasi dan penelitian } \\
\text { mahasiswa. } \\
\text { 6.Dapat menambah wahana } \\
\text { wisata. }\end{array}$ & 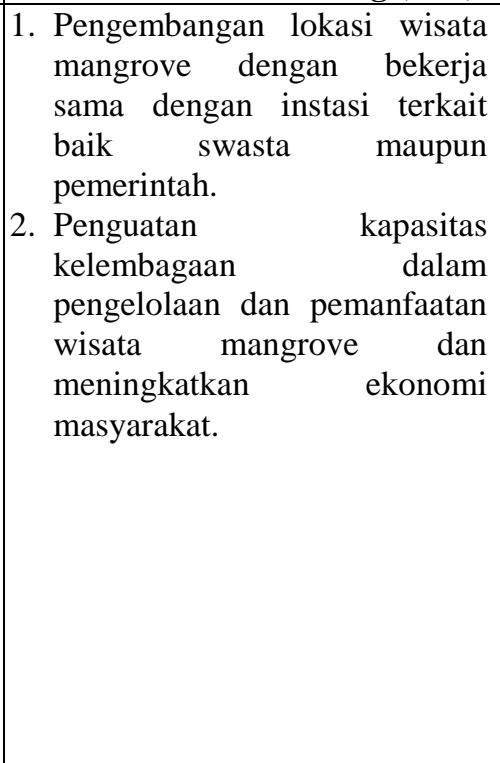 & $\begin{array}{l}\text { 1. Melakukan sosialisasi dan } \\
\text { promosi untuk memperkenalkan } \\
\text { lokasi wisata mangrove. } \\
\text { 2. Penyediaan anggaran untuk } \\
\text { pengembangan serta pengelolaan } \\
\text { dan pemanfaatan wilayah wisata } \\
\text { mangrove. }\end{array}$ \\
\hline ANCAMAN & $\begin{array}{c}\text { Strategi Menggunakan } \\
\text { Kekuatan Untuk Menghadapi } \\
\text { Ancaman } \\
\text { (S-T) }\end{array}$ & $\begin{array}{l}\text { Strategi Mengurangi Kelemahan } \\
\text { Untuk Menghadapi Ancaman (W- } \\
\text { T) }\end{array}$ \\
\hline $\begin{array}{l}\text { 1.Dekatnya lokasi wisata } \\
\text { dengan tambak masyarakat. } \\
\text { 2. Adanya satwa liar seperti : } \\
\text { ular phytton, buaya dan } \\
\text { biawak. } \\
\text { 3. Banyaknya sampah plastik. } \\
\text { 4.Seringnya batang } \\
\text { mangrove yang di } \\
\text { eksploitasi masyarakat. } \\
\text { 5.Area parkir yang masih } \\
\text { dimiliki warga sekitar. } \\
\text { 6.Lokasi wisata mangrove } \\
\text { yang akan dijadikan } \\
\text { pelabuhan kapal. }\end{array}$ & $\begin{array}{l}\text { 1. Penyusunan Peraturan Daerah } \\
\text { (Perda) terhadap pengelolaan } \\
\text { dan pemanfaatan hutan } \\
\text { mangrove. } \\
\text { 2. Meningkatkan rasa } \\
\text { kekeluargaan masyarakat, } \\
\text { swasta, pemerintah serta } \\
\text { pengunjung dalam menjaga } \\
\text { kelestarian sumberdaya dan } \\
\text { pemanfaatan sumberdaya yang } \\
\text { berkelanjutan. }\end{array}$ & $\begin{array}{l}\text { 1. Peningkatankesadaran masyarakat } \\
\text { tentang pentingnya hutan } \\
\text { mangrove untuk semua makhluk } \\
\text { hidup. } \\
\text { 2. Peningkatan pengawasan dan } \\
\text { penegakan hukum di kawasan } \\
\text { wilayah wisata mangrove. }\end{array}$ \\
\hline
\end{tabular}

Sumber : Data Primer, 2019

\section{KESIMPULAN}

Berdasarkan hasil pembahasan dapat ditarik beberapa kesimpulan sebagai berikut : 1) Jenis penyusun komunitas mangrove teritip terdiri dari $A$. alba, N. fruticans, $R$. apiculata, $R$. mucronata dan $S$. alba, yaitu jenis $S$. mendominasi kawasan tersebut. Berdasarkan kondisi ekosistem mangrove di Teritip maka dapat dijadikan sebagai kawasan ekowisata mangrove. 2) Indeks kesesuaian ekowisata mangrove pada stasiun $1(\mathrm{IKW}=67 \%)$, stasiun 2 (IKW $=78 \%)$, dan stasiun $3(\mathrm{IKW}=78 \%)$, sehingga stasiun 1,2 dan 3 termasuk kategori sesuai (S2). Daya dukung kawasan ekowisata mangrove 800 orang/hari, hasil indeks kesesuaian wisata mangrove serta daya dukung kawasan menunjukkan termasuk pada kategori sesuai sangat layak dan mendukung untuk dikembangkan sebagai ekowisata. 3) Prospek dan strategi dalam 
mengembangkan dan mengelola wilayah wisata mangrove di Kelurahan Teritip berdasarkan wilayah lokasi wisata mangrove berada kuadrant I yang artinya bersifat Aggressive, hal ini dapat dilihat bahwa peluang untuk prospek pengembangan wisata mangrove sangat besar sehingga untuk menjadi tempat ini merupakan wisata mangrove yang bagus dan diminati wisatawan terbuka lebar, untuk pengembangan kesejahteraan masyarakat sekitar dengan meningkatkan ekonomi juga sangat menjanjikan.

\section{DAFTAR PUSTAKA}

Bengen, D.G. 2004 Pedoman Teknisi Pengenalan dan Pengelolaan Ekosistem Mangrove. PKSPL-IPB, Bogor.

Djau M.S., 2012. Analisis keberlanjutan perikanan di Kawasan Konservasi Laut Daerah (KKLD) Olele dan Periran Sekitarnya Kabupaten Bone Bolango Provinsi Gorontalo. Tesis. Bogor.

Dahuri, R. 2003. Keanekaragaman Hayati Laut. Aset Pembangunan Berkelanjutan Indonesia. PT. Gramedia Pustaka Utama : Jakarta.

Dahuri R, Y. Rais, S.G. Putra dan M.J. Sitepu. 2001. Pengelolaan Sumberdaya Wilayah Pesisir dan Lautan secara Terpadu. PT. Pradnya Paramita : Jakarta.

Gunn, Clare A., 1994. Tourism Planning : Basic, Concepts dan Cases. Taylor \& Francis : Washington Dc.
Harger, J.R.E., 1982. Major Problems in the Functional Analysis Of Mangroves in South East Asia, h 20-22. Paper presented at the Symposium on Mangrove Forest Ecosystem Productivity, Bogor.

Indriyanto, 2006. Ekologi Hutan. Penerbit PT Bumi Aksara : Jakarta.

Jayanti, J. G. 2009. The Impact of MCommerce in Global Perspectives. A Swot Analysis.

Nagelkerken I, S.J.M. Blaber, S. Bouillon, P. Green, M. Haywood, L.G. Kirton, J. Meynecke, O. Pawlik, J. Penrose, H.M. Sasekumar, P.J Somerfield. 2008. The Habitat Function of Mangroves for Terrestrial and Marine Fauna: A Review. Journal Aquatic Botany, 89: 55-185.

Noor, Y.R. 2006. Panduan Pengenalan Mangrove di Indonesia. Wetland International - Indonesia Programme. Bogor.

Nuddin Harahab, Penilaian Ekonomi Ekosistem Hutan Mangrove dan Aplikasinya dalam Perencanaan Wilayah Pesisir, (Yogyakarta:Graha Ilmu, 2010), cet.1, hlm. 29.

Saenger, P, E.J. Hegerl, and J.D.S. Davie, 1983. Global Status of Mangrove Ecosystems. IUCN. Commision on Ecology No. 3.

Santoso, 2003. Pengembangan Ukm berbasis ekowisata. Download www.pnm.co.id 
Sugiyono, 2007. Metode penelitian pendidikan pendekatan kuantitatif, kualitatif $\mathrm{R}$ dan $\mathrm{D}$. Bandung : Alfabeta.

Sulaksmi, R. 2007. Analisis dampak Pariwisata terhadap Pendapatan dan Kesejahteraan Masyarakat sekitar Kawasan Taman Wisata Alam Laut Pulau Weh Kota Sabang. Tesis Sekolah Pasca Sarjana Institut Pertanian Bogor. Bogor.

Suyatna I., et al., 2013. Sebaran Terumbu karang, kondisi dan spesies karang di Kecamatan Muara Badak Kabupaten Kutai Kartanegara. Laporan Akhir Mapping. Tenggarong.

Imanuddin, 2012. Analisis Vegetasi Kawasan Hutan Mangrove di Teluk Pangempang Kecamatan Muara Badak Kabupaten Kutai Kartanegara. Tesis Magister PS Ilmu Kehutanan, Universitas Mulawarman.
Tuwo, A. 2011. Pengelolaan Ekowisata Pesisir dan Laut. Brilian Internasional : Surabaya.

Waryono (1973) ; Saenger et al. (1983), dan Kusmana (1993),

Yulianda, 2007. Ekowisata bahari sebagai alternatif pemanfaatan sumberdaya pesisir berbasis konservasi. seminar sains departemen sumberdaya perairan. Fakultas Perikanan dan Ilmu Kelautan. IPB Bogor, 21 Februari 2007. 